\title{
Adrenal metastasis as the initial diagnosis of synchronous papillary and follicular thyroid cancer
}

\author{
Xin $\mathrm{He}^{1 *} \mathrm{D}$, Scott A. Soleimanpour ${ }^{1,2}$ and Gregory A. Clines ${ }^{1,2}$
}

\begin{abstract}
Background: Differentiated thyroid cancer uncommonly presents with distant metastases. Adrenal metastasis from differentiated thyroid cancer presenting as the initial finding is even less common.

Case Presentation: A 71-year-old male was incidentally found on chest $C T$ to have bilateral thyroid nodules, which were confirmed on ultrasound. Fine needle aspiration of the dominant right $3.3 \mathrm{~cm}$ nodule contained histologic features most consistent with Bethesda classification III, and repeat fine needle aspiration revealed pathology consistent with Bethesda classification II. Follow-up thyroid ultrasound showed 1\% increase and 14\% increase in nodule volume at one and two years, respectively, compared to baseline. Prior to the second annual thyroid ultrasound, the patient was incidentally found to have a $4.1 \mathrm{~cm}$ heterogeneously enhancing mass in the right adrenal gland on CT of the abdomen and pelvis. Biochemical evaluation was unremarkable with the exception of morning cortisol of $3.2 \mu \mathrm{g} / \mathrm{dL}$ after dexamethasone suppression. The patient then underwent laparoscopic right adrenal gland excision, which revealed metastatic follicular thyroid carcinoma. Total thyroidectomy was then performed, with pathology showing a $4.8 \mathrm{~cm}$ well-differentiated follicular thyroid carcinoma of the right lobe, a $0.5 \mathrm{~cm}$ noninvasive follicular thyroid neoplasm with papillary-like nuclear features of the left lobe, and a $0.1 \mathrm{~cm}$ papillary microcarcinoma of the left lobe. Thyrotropin-stimulated whole body scan showed normal physiologic uptake of the remnant thyroid tissue without evidence of other iodine avid disease. The patient then received radioactive iodine. At follow-up 14 months after total thyroidectomy, he remains free of recurrent disease.
\end{abstract}

Conclusion: Despite following the recommended protocol for evaluation and surveillance of thyroid nodules, thyroid cancer can be challenging to diagnose, and may not be diagnosed until distant metastases are identified.

Keywords: Differentiated thyroid cancer, Thyroid cancer metastasis, Metastases to adrenal glands

\footnotetext{
* Correspondence: xihe@med.umich.edu

'Department of Internal MedicineDivision of MetabolismEndocrinology \& Diabetes, University of Michigan, 1500 East Medical Center Drive, Ann Arbor, MI 48109, USA

Full list of author information is available at the end of the article
}

(c) The Author(s). 2020 Open Access This article is licensed under a Creative Commons Attribution 4.0 International License, which permits use, sharing, adaptation, distribution and reproduction in any medium or format, as long as you give appropriate credit to the original author(s) and the source, provide a link to the Creative Commons licence, and indicate if changes were made. The images or other third party material in this article are included in the article's Creative Commons licence, unless indicated otherwise in a credit line to the material. If material is not included in the article's Creative Commons licence and your intended use is not permitted by statutory regulation or exceeds the permitted use, you will need to obtain permission directly from the copyright holder. To view a copy of this licence, visit http://creativecommons.org/licenses/by/4.0/ The Creative Commons Public Domain Dedication waiver (http://creativecommons.org/publicdomain/zero/1.0/) applies to the data made available in this article, unless otherwise stated in a credit line to the data. 


\section{Background}

Thyroid cancer is the most common endocrine malignancy and twelfth most common cancer in the United States [1]. Differentiated thyroid carcinomas (DTC) account for the vast majority of all thyroid cancer cases, of which roughly $80 \%$ are papillary thyroid carcinoma (PTC) and 10-15\% are follicular thyroid carcinoma (FTC) [2],medullary and anaplastic thyroid cancer make up the remaining $5 \%$ of cases. The concurrent presentation of multiple histologic types of thyroid cancer in the same patient is rare, accounting for approximately $0.06 \%$ of thyroid cancers in database analyses [3]. Amongst DTC, prognosis is excellent for most patients, even for the $20-50 \%$ of cases that present with local metastases [4]. However, more aggressive disease can be seen; approximately $2-3 \%$ of DTC cases present with distant metastases on diagnosis $[5,6]$. We report a case of DTC manifesting with both PTC and FTC, which was diagnosed on evaluation of adrenal metastasis.

\section{Case presentation}

A 71-year-old male with past medical history of hypertension, type 2 diabetes, stage 3 chronic kidney disease, kidney stones, intraductal papillary mucinous neoplasm status post distal pancreatectomy, and 50-pack-year smoking history, was incidentally found on surveillance chest CT of pulmonary nodules to have bilateral thyroid nodules. Thyroid ultrasound confirmed a dominant $3.3 \times 2.2 \times 1.8 \mathrm{~cm}$ right thyroid nodule with heterogeneous echogenicity, mixed solid and cystic composition, lobulated borders, without echogenic foci, and without increased vascularity (Fig. 1a). Multiple sub-centimeter left thyroid nodules that were hypoechoic, cystic, wider than tall, with smooth margins, without echogenic foci, and without increased vascularity, were also noted (Fig. 1b). No lymphadenopathy in the neck was

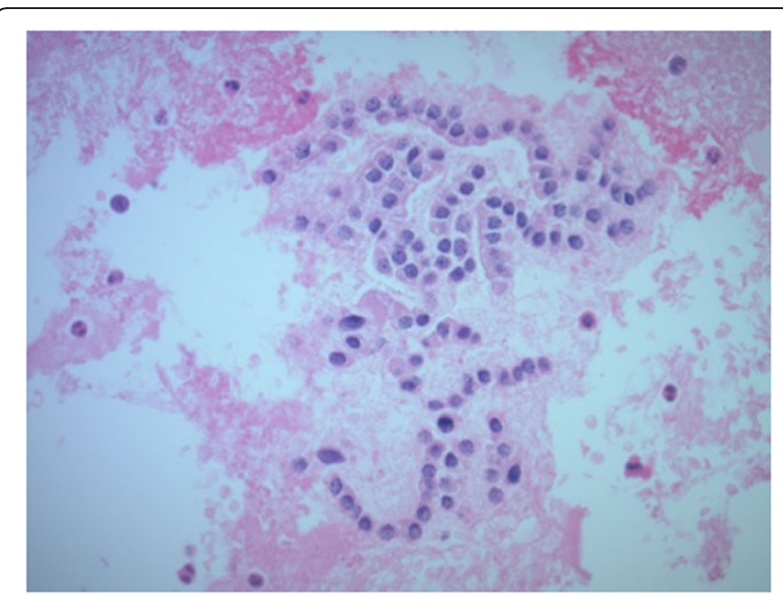

Fig. 2 Fine needle aspiration of dominant right thyroid nodule: hypercellular aspirate with follicular epithelial cells in sheets and microfollicles, some with Hurthle cell changes and colloid in the background, without significant atypia

(hematoxylin-eosin stain, $\times 400$ )

identified. Fine needle aspiration (FNA) of the dominant right thyroid nodule reported a hypercellular aspirate with follicular epithelial cells in sheets and microfollicles, some with Hurthle cell changes and colloid in the background, without significant atypia (Fig. 2). These features were considered to be most consistent with Bethesda classification III, follicular lesion of undetermined significance (FLUS). Repeat FNA of the same nodule three months later showed benign appearing follicular epithelial cells in few microfollicles groups and many with Hurthle cell changes amid scant colloid, consistent with a benign colloid nodule, Bethesda classification II. Molecular testing was not completed with either FNA. Follow-up thyroid ultrasound completed annually for the next two years showed gradual growth of the right dominant nodule to $3.2 \times 2.3 \times 1.8 \mathrm{~cm}$ at one year $(1 \%$

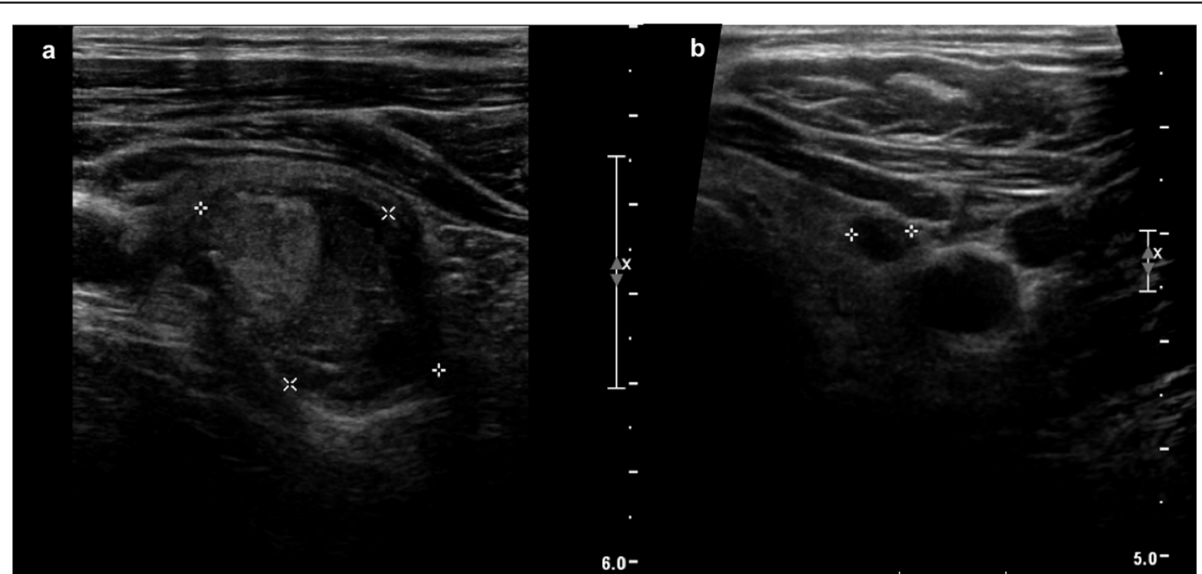

Fig. 1 Thyroid ultrasound. a. Dominant $3.3 \times 2.2 \times 1.8 \mathrm{~cm}$ right thyroid nodule with heterogeneous echogenicity, mixed solid and cystic composition, lobulated borders, without echogenic foci, and without increased vascularity. b. One of several sub-centimeter left thyroid nodules that were hypoechoic, cystic, wider than tall, with smooth margins, without echogenic foci, and without increased vascularity 
increase in volume) and $3.3 \times 2.5 \times 1.8 \mathrm{~cm}$ at two years ( $14 \%$ increase in volume compared to baseline); the smaller left nodules remained sub-centimeter in size without interval change in ultrasound features.

Two months prior to the second annual thyroid ultrasound, the patient underwent CT of the abdomen and pelvis for evaluation of new onset microscopic hematuria and was incidentally noted to have a $4.1 \mathrm{~cm}$ heterogeneously enhancing mass in the right adrenal gland. No enlarged lymph nodes were observed. In retrospect, this had grown from the heterogeneous $1.8 \mathrm{~cm}$ nodule on imaging completed two years prior (on the same CT that first identified the thyroid nodules, though the adrenal finding was not reported at the time) and new when compared to imaging nine years prior. On whole body ${ }^{18}$ F-FDG PET/CT, the adrenal nodule had minimal FDG avidity (maximum SUV of 2.7) (Fig. 3a), but the right thyroid nodule had high peripheral FDG avidity (maximum SUV of 12.7) (Fig. 3b). Biochemical evaluation was negative for primary aldosteronism (plasma renin activity $13.7 \mathrm{ng} / \mathrm{mL} / \mathrm{hr}$, aldosterone $18.4 \mathrm{ng} / \mathrm{dL}$ ) and pheochromocytoma (plasma metanephrines $0.24 \mathrm{nmol} /$ $\mathrm{L}$, plasma normetanephrines $18.4 \mathrm{ng} / \mathrm{dL}$ ). Overnight $1 \mathrm{mg}$ dexamethasone suppression resulted in a borderline morning cortisol of $3.2 \mu \mathrm{g} / \mathrm{dL}$, but late night salivary cortisol was measured twice thereafter and within normal range, $0.055 \mu \mathrm{g} / \mathrm{dL}$ and $0.060 \mu \mathrm{g} / \mathrm{dL}$; 24-h urinary free cortisol testing was not completed. The patient did not have any clinical signs or symptoms suggestive of cortisol excess. The patient then underwent laparoscopic right adrenal gland excision due to concern for malignancy. Pathology revealed metastatic follicular thyroid carcinoma, which stained positive for thyroglobulin (Figs. 4a and 4b).

Total thyroidectomy was then performed. Pathologic evaluation reported a $4.8 \mathrm{~cm}$ well-differentiated FTC of the right lobe (Figs. 5a and b), a $0.5 \mathrm{~cm}$ noninvasive follicular thyroid neoplasm with papillary-like nuclear features (NIFTP) of the left lobe, and a $0.1 \mathrm{~cm}$ papillary microcarcinoma of the left lobe with negative margins
(Fig. 6). Background multinodular hyperplasia and lymphatic invasion were observed, but the margins were negative and no extra-thyroidal extension noted; lymph node dissection was not completed. Serum thyroglobulin was $7.8 \mathrm{ng} / \mathrm{mL}$ seven weeks after total thyroidectomy. Thyrotropin-stimulated ${ }^{131}$ I whole body scan reported normal physiologic uptake of the remnant thyroid tissue without evidence of other iodine avid disease. The patient then received $106.8 \mathrm{mCi}$ of ${ }^{131} \mathrm{I}$, and postradioactive ${ }^{131}$ I whole body scan revealed no new foci of iodine avid disease. Eight months after total thyroidectomy, serum thyroglobulin decreased to $0.1 \mathrm{ng} / \mathrm{mL}$ with negative thyroglobulin antibodies. At follow-up 14 months after total thyroidectomy, the patient's thyroglobulin level remained low, $0.1 \mathrm{ng} / \mathrm{mL}$, and he was continued on suppressive levothyroxine treatment with thyroid stimulating hormone level of $0.019 \mathrm{uIU} / \mathrm{mL}$.

\section{Discussion and conclusions}

Multiple features of this patient case were unusual. Firstly, the diagnosis of thyroid malignancy was not made until the patient presented with a rare location for distant metastases. Second, the patient underwent multiple fine needle aspirations of the dominant right nodule, ultimately yielding reassuring pathology, and surveillance imaging showed stability for years-yet the patient was later found to have thyroid cancer. Finally, the patient was found to have different histologic types of thyroid malignancy in each thyroid lobe.

Only 2-3\% of DTC cases present with distant metastases on diagnosis $[5,6]$. Risk factors for presentation with distant metastases include male sex, age greater than 45 , non-Caucasian race, tumor size greater than $40 \mathrm{~mm}$, and FTC. Male sex, older age, tumor size, and FTC diagnosis were relevant risk factors in our patient. In FTC specifically, the most common sites of distant metastases are bone (42\%), lung (33\%), and brain (17\%) [7], which have been attributed primarily to hematogenous spread [8]. Adrenal metastases are rare, accounting for approximately $1.7 \%$ of DTC distant metastases [9], with only

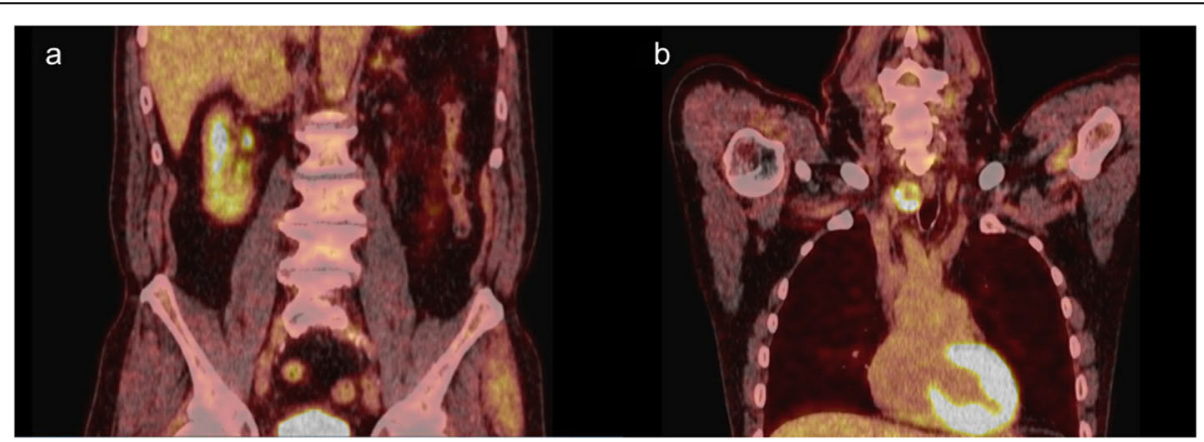

Fig. $3{ }^{18}$ F-FDG PET/CT: a. The right adrenal mass has mild homogeneous activity (maximum SUV of 2.7), which is similar to the activity to the liver. b. Posterior aspect of the right lobe of the thyroid gland is primarily peripherally FDG avid (maximum SUV of 12.7) 


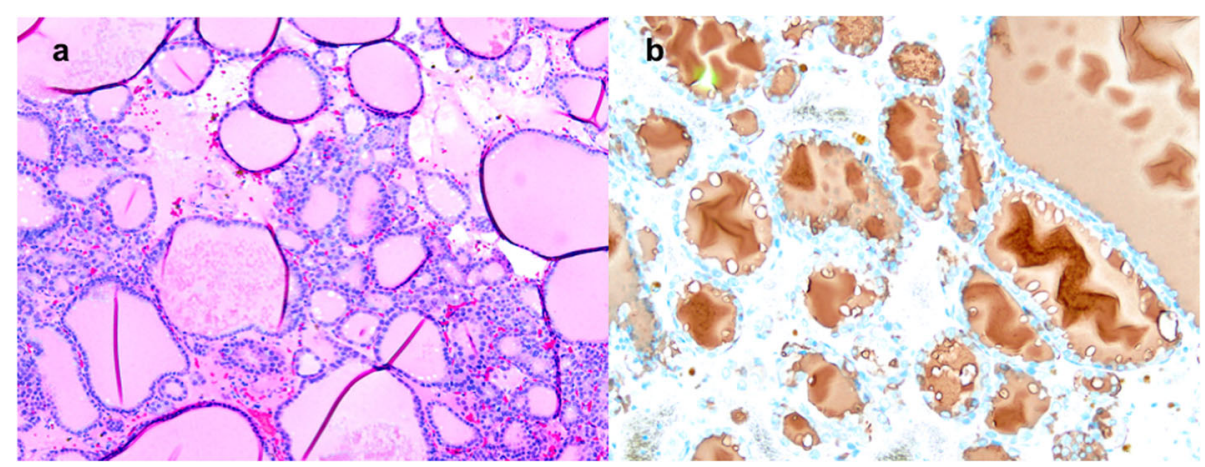

Fig. 4 a. Right adrenal gland surgical pathology: metastatic follicular thyroid carcinoma (hematoxylin-eosin stain, $\times 100$ ). b. Right adrenal gland surgical pathology: metastatic follicular thyroid carcinoma with positive thyroglobulin stain (thyroglobulin immunostain, $\times 100$ )

seven cases of FTC with metastases to the adrenal gland reported in the literature [9-15]. In four cases, the diagnoses of adrenal gland metastases were made during the initial workup following diagnosis of FTC, while the other three diagnoses were made during FTC surveillance, 3-12 years after initial diagnosis. Of the six cases reporting the imaging modality that identified the adrenal metastases, four cases employed ${ }^{131}$ I whole body scan alone, and two used ${ }^{131}$ I-SPECT/CT. Of note, one adrenal lesion was negative on ${ }^{131} \mathrm{I}$ whole body scan, but was identified on CT imaging. Only one case also utilized ${ }^{18} \mathrm{~F}$-FDG PET/CT, which revealed a high maximum SUV of 9.5 in the adrenal lesion. Three cases were treated with radioactive iodine, three underwent adrenalectomy, and one treated with gamma knife radiosurgery. Of the five cases reporting clinical outcome at the time of publication, all but one case reported the patients were alive.

Compared to prior reports, our case is unique in its clinical course, with the identification of the adrenal gland metastasis leading to the diagnosis of FTC, rather than the reverse. This is also only the second case to report lack of uptake of the adrenal metastasis on the ${ }^{131} \mathrm{I}$ whole body scan. In contrast to the one other case that utilized ${ }^{18}$ F-FDG PET/CT, the adrenal metastasis in our case did not have high FDG avidity.

Another unusual feature of this case was the patient's initial presentation of incidental thyroid nodules. It is notable that the first FNA result had features felt to be consistent with FLUS, prompting repeat aspiration, which resulted as a benign colloid nodule. It is possible the benign nodule transformed into a carcinoma following FNA. An estimated $2 \%$ of thyroid malignancies arise from preexisting benign thyroid nodules, and analyses of tumor markers in thyroid nodules suggest that some follicular and Hurthle cell adenomas may be precursors to carcinomas [16]. Thus, perhaps our patient's nodule was, in fact, a follicular adenoma. It is also possible the benign FNA result was a false negative. Retrospective studies suggest that false negative FNA cases occur $4-6 \%$ of the time and can be attributed to both sampling error [17], as well as interpretation error in nearly equal proportion [18]. While intuitively larger nodules may be associated with greater sampling error $[19,20]$, other data suggests this has not been consistently observed [21, 22]. With respect to interpretation error, literature suggests

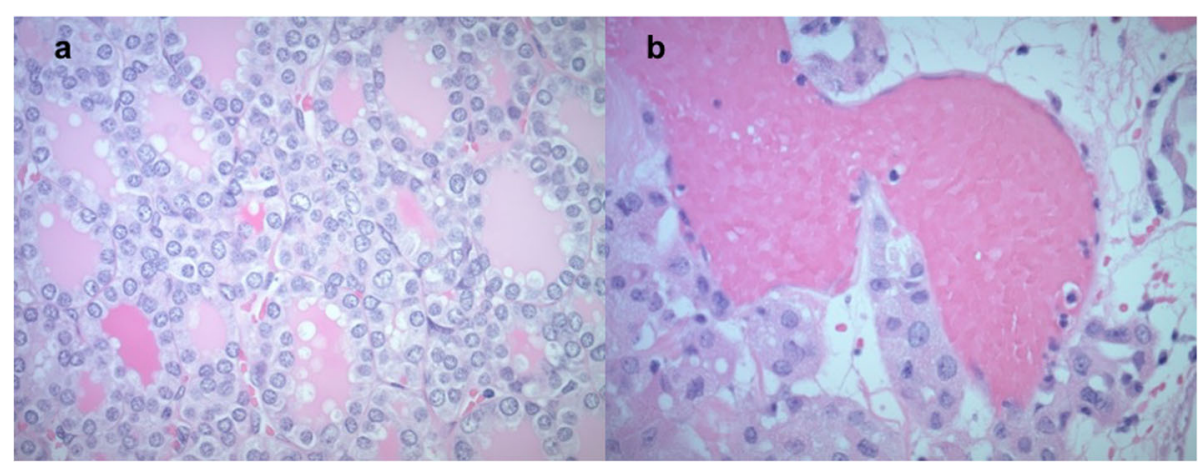

Fig. 5 Right thyroid lobe surgical pathology: Follicular carcinoma of the right lobe (a), well-differentiated $4.8 \mathrm{~cm}$ with capsular invasion and probable lymphovascular invasion (b), confined to thyroid (hematoxylin-eosin stain, $\times 400$ ) 


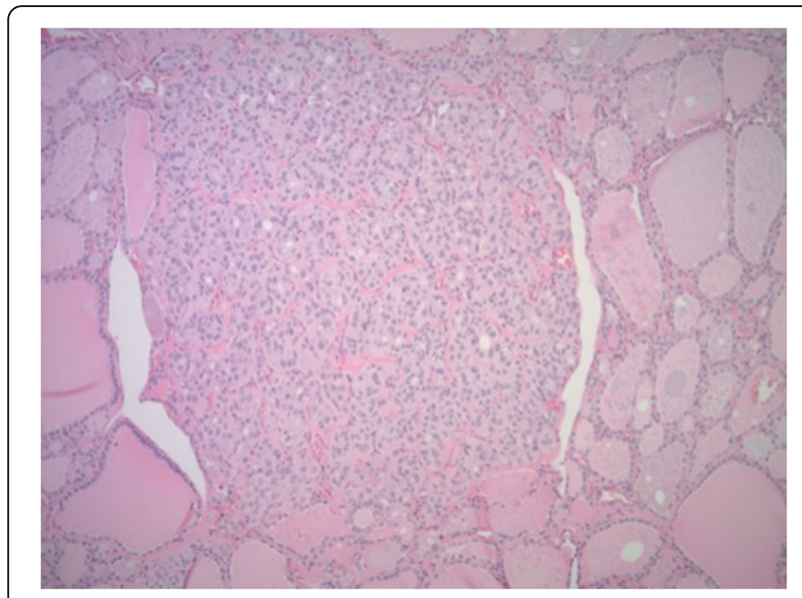

Fig. 6 Left thyroid lobe surgical pathology: Papillary microcarcinoma of the left lobe $0.1 \mathrm{~cm}$, confined to the thyroid with negative margins, and with background multinodular hyperplasia (hematoxylin-eosin stain, $\times 40$ )

follicular neoplasms are more commonly misinterpreted than non-follicular lesions, the former making up $79 \%$ of interpretation error cases [18]. In this patient, risk factors for potentially a false negative FNA include the thyroid nodule size as well as presence of follicular neoplasm.

Our patient was ultimately diagnosed with FTC of the right lobe, NIFTP of the left lobe, and papillary microcarcinoma of the left lobe. While not as exceptional as reports of concurrent presentation of DTC with medullary or anaplastic thyroid carcinoma [23-25], the presence of multiple subtypes of thyroid carcinoma in the same patient is rare [3]. The simultaneous occurrence of both follicular and papillary neoplasms can be attributed to their common cellular origin from follicular epithelial thyroid cells involved in iodine metabolism [26].

This case is unexpected in both its presentation as well as the ultimate diagnosis. It demonstrates that the diagnosis of DTC can be challenging, even in the setting of following the recommended protocol for evaluation and surveillance of thyroid nodules.

\section{Acknowledgements}

We thank Maria Papaleontiou for her critical review of the manuscript.

\section{Authors' contributions}

GAC and SAS conceived the idea of reporting this case. XH drafted the work. GAC and SAS substantively revised it. All authors have read and approved the final manuscript.

\section{Funding}

$\mathrm{XH}$ is supported by grant T32DK07245 from the National Institutes of Diabetes and Digestive and Kidney Diseases.

Availability of data and materials Not applicable.

\section{Ethics approval and consent to participate}

Not applicable.

\section{Consent for publication}

The patient consented to publication of his medical history.

\section{Competing interests}

The authors declare that they have no competing interests.

\section{Author details}

${ }^{1}$ Department of Internal MedicineDivision of MetabolismEndocrinology \& Diabetes, University of Michigan, 1500 East Medical Center Drive, Ann Arbor, Ml 48109, USA. ${ }^{2}$ Veterans Affairs Ann Arbor Healthcare System, 2215 Fuller Road, Ann Arbor, Ml 48105, USA.

Received: 17 August 2020 Accepted: 25 October 2020

Published online: 04 November 2020

\section{References}

1. Cancer of the Thyroid - Cancer Stat Facts [Internet]. SEER. [cited 2020 Sep 4]. Available from: https://seer.cancer.gov/statfacts/html/thyro.html.

2. Aschebrook-Kilfoy B, Grogan RH, Ward MH, Kaplan E, Devesa SS. Follicular Thyroid Cancer Incidence Patterns in the United States, 1980-2009. Thyroid. 2013;23(8):1015-21.

3. Liu C, Zhao Q, Li Z, Wang S, Xiong Y, Liu Z, et al. Mixed subtype thyroid cancer: A surveillance, epidemiology, and end results database analysis. Oncotarget. 2017;8(49):86556-65.

4. Haugen BR, Alexander EK, Bible KC, Doherty GM, Mandel SJ, Nikiforov YE, et al. 2015 American Thyroid Association Management Guidelines for Adult Patients with Thyroid Nodules and Differentiated Thyroid Cancer: The American Thyroid Association Guidelines Task Force on Thyroid Nodules and Differentiated Thyroid Cancer. Thyroid. 2016;26(1):1-133.

5. Goffredo P, Sosa JA, Roman SA. Differentiated Thyroid Cancer Presenting with Distant Metastases: A Population Analysis Over Two Decades. World J Surg. 2013;37(7):1599-605.

6. Vuong HG, Duong UNP, Pham TQ, Tran HM, Oishi N, Mochizuki K, et al. Clinicopathological Risk Factors for Distant Metastasis in Differentiated Thyroid Carcinoma: A Meta-analysis. World J Surg. 2018;42(4):1005-17.

7. Parameswaran R, Shulin HuJ, Min En N, Tan W, Yuan N. Patterns of metastasis in follicular thyroid carcinoma and the difference between early and delayed presentation. Ann R Coll Surg Engl. 2017;99(2):151-4.

8. Giorgadze TA, Baloch ZW, Pasha T, Zhang PJ, LiVolsi VA. Lymphatic and blood vessel density in the follicular patterned lesions of thyroid. Mod Pathol. 2005;18(11):1424-31.

9. Farina E, Monari F, Tallini G, Repaci A, Mazzarotto R, Giunchi F, et al. Unusual Thyroid Carcinoma Metastases: a Case Series and Literature Review. Endocr Pathol. 2016;27(1):55-64.

10. Ranade R, Thapa P, Basu S. Adrenal metastasis from differentiated thyroid carcinoma documented on post-therapy 1311 scan: A case based discussion. World J Radiol. 2014;6(3):56-61.

11. Zhao Z, Shen G, Liu B, Kuang A. Unusual Adrenal and Brain Metastases From Follicular Thyroid Carcinoma Revealed by 131 I SPECT/CT. Clin Nucl Med. 2016;41(1):e53.

12. Xue Y-L, Song H-J, Qiu Z-L, Luo Q-Y. An Unusual 1311-Avid Adrenal Metastasis From Follicular Thyroid Carcinoma Identified by 1311-SPECT/CT. Clin Nucl Med. 2012;37(9):e229.

13. Girelli ME, Casara D, Rubello D, Piccolo M, Piotto A, Pelizzo MR, et al. Metastatic thyroid carcinoma of the adrenal gland. J Endocrinol Invest. 1993;16(2):139-41.

14. Kumar A, Nadig M, Patra V, Srivastava DN, Verma K, Bal CS. Adrenal and renal metastases from follicular thyroid cancer. Br J Radiol. 2005;78(935): 1038-41.

15. FerrerGarcía J, Merino Torres J, Ponce Marco J, Piñón Sellés F. Unusual metastasis of differentiated thyroid carcinoma. An Med InternaMadr Spain 1984. 2002;19(11):579-82.

16. Arora N, Scognamiglio T, Zhu B, Fahey TJ III. Do Benign Thyroid Nodules Have Malignant Potential? An Evidence-Based Review World J Surg. 2008; 32(7):1237-46.

17. Yu X-M, Patel PN, Chen H, Sippel RS. False-negative fine-needle aspiration of thyroid nodules cannot be attributed to sampling error alone. Am J Surg. 2012;203(3):331-4 (discussion 334). 
18. Abi-Raad R, Prasad M, Baldassari R, Schofield K, Callender GG, Chhieng D, et al. The Value of Negative Diagnosis in Thyroid Fine-Needle Aspiration: a Retrospective Study with Histologic Follow-Up. Endocr Pathol. 2018;29(3): 269-75.

19. McHenry CR, Huh ES, Machekano RN. Is nodule size an independent predictor of thyroid malignancy? Surgery. 2008;144(6):1062-9.

20. Pinchot SN, Al-Wagih H, Schaefer S, Sippel R, Chen H. Accuracy of FineNeedle Aspiration Biopsy for Predicting Neoplasm or Carcinoma in Thyroid Nodules $4 \mathrm{~cm}$ or Larger. Arch Surg. 2009;144(7):649-55.

21. Shrestha M, Crothers BA, Burch HB. The Impact of Thyroid Nodule Size on the Risk of Malignancy and Accuracy of Fine-Needle Aspiration: A 10-Year Study from a Single Institution. Thyroid. 2012;22(12):1251-6.

22. Rosario PW, Salles DS, Bessa B, Purisch S. Low false-negative rate of cytology in thyroid nodules $>4 \mathrm{~cm}$. Arq Bras Endocrinol Amp Metabol. 2009;53(9): $1143-5$.

23. Cupisti K, Raffel A, Ramp U, Wolf A, Donner A, Krausch M, et al. Synchronous occurrence of a follicular, papillary and medullary thyroid carcinoma in a recurrent goiter. Endocr J. 2005;52(2):281-5.

24. Verdi D, Pennelli G, Galuppini F, Pelizzo MR, Toniato A. Synchronous medullary, papillary and follicular carcinomas in the same thyroid: case report and review of literature. Updat Surg. 2013;65(4):329-32.

25. Mohammadzadeh M, Pourzand A, Eftekhar-Sadat A-T, Alikhah H, NaghaviBehzad M. A case of concurrent several forms of thyroid cancer. Niger Med J J Niger Med Assoc. 2013;54(5):351-3.

26. Pstrąg N, Ziemnicka K, Bluyssen $\mathrm{H}$, Wesoły J. Thyroid cancers of follicular origin in a genomic light: in-depth overview of common and unique molecular marker candidates. Mol Cancer [Internet]. 2018 Aug 8 [cited 2020 Jun 23];17. Available from: https://www.ncbi.nlm.nih.gov/pmc/articles/PMC6 081953/.

\section{Publisher's Note}

Springer Nature remains neutral with regard to jurisdictional claims in published maps and institutional affiliations.

Ready to submit your research? Choose BMC and benefit from:

- fast, convenient online submission

- thorough peer review by experienced researchers in your field

- rapid publication on acceptance

- support for research data, including large and complex data types

- gold Open Access which fosters wider collaboration and increased citations

- maximum visibility for your research: over $100 \mathrm{M}$ website views per year

At $\mathrm{BMC}$, research is always in progress.

Learn more biomedcentral.com/submissions 